\title{
ANALYSIS OF LIMONENE AND OTHER ANTIOXIDANTS IN COMMERCIAL ESSENTIAL OIL PRODUCTS COMPARED TO HOMEMADE VIRGIN COCONUT OIL
}

\author{
Ni Made Suaniti ${ }^{*}$, I Wayan Bandem Adnyana², Manuntun Manurung1, Oka \\ Ratnayani $^{1}$, and Raisyah Anjani ${ }^{1}$ \\ ${ }^{1}$ Chemistry Study Program, Mathematic and Natural Sciences Faculty, Udayana University, Bukit \\ Jimbaran, Badung, Bali, Indonesia 80361 \\ ${ }^{2}$ Mechanical Engineering Study Program, Engineering Faculty, Udayana University, Bukit Jimbaran, \\ Badung, Bali, Indonesia 80361 \\ *Corresponding author: madesuaniti@unud.ac.id
}

\begin{abstract}
Essential oil production in the market is very diverse with various brands labeled as antioxidants that have gained more attention in the society recently. The purpose of this study was to analyze limonene and other antioxidants content of the essential oils in the market compared to homemade virgin coconut oil. The method used was Gas Chromatography Mass Spectrometry (GC-MS) and Fourier-transform infrared (FTIR) Spectroscopy. The infrared spectrogram showed the presence of alkanes and esters respectively at wave numbers of 3000-2850 and 1750-1730 $\mathrm{cm}^{-1}$. Chromatogram results showed the presence of limonene compounds and some antioxidants with a fairly good separation in the several types of oils, which was not detected in the homemade virgin coconut oil.
\end{abstract}

Keywords: antioxidants, limonene, product oil, virgin coconut oil

\section{INTRODUCTION}

Refresher oil with brand "Fresh" that has been used by the society recently continues to raise attention and developed more following the development of science and technology, which is also supported by the current availability of a variety of scents. Meanwhile, virgin coconut oil is also very potential and beneficial to be used as refresher oil.

Therefore, it is necessary to develop more attracted scents as well as conduct chemically qualitative and quantitative analysis for homemade virgin coconut oil compared to the commercial product of essential oils. The qualitative analysis can be done by suspecting the functional groups by using infrared spectroscopy, and also the appearance of the compounds that can be determined by gas chromatography through retention time and mass spectrometry as ion fragments $(\mathrm{m} / \mathrm{z})$. The oil content in the essential oils which are volatile compounds, namely antioxidants, varies greatly both in the chemical structure and amount. The percentage of volatile compound such as limonene in the essential oils from plants is determined by GC-MS (Derwich et al., 2010; 
Ibrahimi et al., 2013). Pinene compounds in the essential oils that are also detected in small amounts as volatile compounds through extraction methods (Tomasz et al., 2013). Active compounds in essential oils are also found qualitatively and quantitatively using GC-MS (Kaluzna-Czaplinska, 2007).

The quality of oil is very dependent on the method of preparation and analysis. The amount and variety of chemical compounds of oil from plants requires an easy and fast analysis effort such as GC-MS. This research was developed to analyze the limonene compounds and other antioxidants in the commercial essential oils product compared to homemade virgin coconut oil.

\section{MATERIALS AND METHODS}

The materials used were homemade virgin coconut oil, commercial essential oil products marked as Fc, F, A, P, and MA, ethanol pro analysis, and the equipments were volumetric flask, glass beaker, Fouriertransform infrared spectroscopy (FTIR) Prestige 21, and Gas Chromatography-Mass Spectrometry (GCMS) Shimadzu 210 Ultra.

FTIR method is one of the modern and simple qualitative analysis methods which use infrares radiation to change the vibration energy of a molecule or polyatomic ion. Vibration energy is determined by the strength of the bond and the mass of the molecule that can be characterized based on the type of bond such as a single carbon alkane bond (C-C), a double/alkene bond $(\mathrm{C}=\mathrm{C})$, and a carbonyl bond $(\mathrm{C}=\mathrm{O})$. Carbonyl bonds are very sensitive, for example acids appear at wave number of $1650 \mathrm{~cm}^{-1}$, ketones at $1700 \mathrm{~cm}^{-1}$, esters at $1750 \mathrm{~cm}^{-1}$, and chloride at $1800 \mathrm{~cm}^{-1}$ (Harvey, 2000; Silverstein et al., 1991).

GC-MS is a modern method consisting of Gas Chromatography (GC) which interfaces with Mass Spectrometry (MS). The process starts with separation followed by identification of atomic mass per ion $(\mathrm{m} / \mathrm{z})$, so that GC-MS using detectors used as a qualitative analysis method is mass spectrometry. However, chromatography gas can also be combined with FTIR. The spectra information can often be used to identify liquid samples (Harvey, 2000). Furthermore GC-MS is widely used for the analysis of drug samples, food, and cosmetics spedifically for volatile compounds.

Identification of functional groups and atomic mass of essential oil or virgin coconut oil (VCO) samples can be analyzed by FTIR and GC-MS. VCO as an organic compound containing elements of carbon, hydrogen, and oxygen is subjected to infrared radiation which has a frequency (wave number of 500-4000 cm-1) that will be absorbed and then measured as percentage transmittance $(\% \mathrm{~T})$. The compounds contained in VCO can also be separated by 
gas chromatography and continue to be identified based on separate peaks as mass per ion by mass spectrometry.

\section{RESULTS AND DISCUSSION}

GC-MS analysis of compounds contained in fresh oils in the market marked with the codes Fc, Sc, A, P, and MA resulted in limonene compound with ion fragments $(\mathrm{m} / \mathrm{z})$ of 68 and the alleged antioxidant compounds such as alpha pinene, delta 3 carene, beta pinene, and alpha phelandrene with $\mathrm{m} / \mathrm{z}$ of 93 as shown in Table 1 . The limonene $(1,8-p$-menthadiene $=1$-methyl-4(1- methylethenyl-cyclohexene) (Erasto and Viljoen, 2008) structure for example one of antioxidant in accordance with the literature as can be seen in Fig. 1.

Table 1. The presence of limonene and some antioxidants in fresh oil in GC-MS

\begin{tabular}{llllll}
\hline & \multicolumn{5}{c}{ Area x 1000000 } \\
Compounds & Fc & Sc & A & P & MA \\
\hline Alpha pinene (m/z 93) & n.d & 6.1 & 0 & 26.6 & 5.2 \\
Delta-3-carene (m/z 93) & n.d & n.d & 0 & 1.1 & n.d \\
Beta pinene (m/z 93) & 6.7 & 12.4 & 15.1 & 2.7 & n.d \\
Alpha phelandrene (m/z 93) & n.d & 0.8 & n.d & 4.1 & 15.8 \\
dl Limonene (m/z 68) & n.d & n.d & 46.9 & 6.1 & 9.7 \\
\hline
\end{tabular}

n.d $=$ no detection

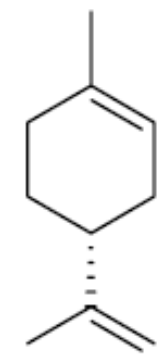

A

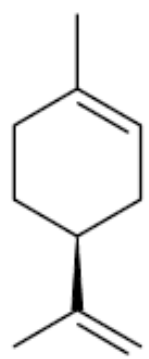

B

Fig. 1. Structure of $R-(+)$ limonene (A) and $S-(-)$ limonene (B) (Erasto and Viljoen, 2008)

Similar function group detected using indicated by sharp absorption at wave infrared spectrograms are shown as in Fig. 2, numbers $3000-2850 \mathrm{~cm}^{-1}$, alkenes at 1680 alleged alkanes, alkenes, and esters were $1600 \mathrm{~cm}^{-1}$ and carbonyl between 1820-1600 detected. Alleged group alkanes were $\mathrm{cm}^{-1}$ supported by ester groups at 1750-1730 
$\mathrm{cm}^{-1}$ very weak. The $\mathrm{Fc}$ sample had the homemade virgin coconut oil as a control strongest absorption and sharp band shape (VCOc).

indicating the highest concentration of the compound content of the other two samples (A and $\mathrm{Sc}$ ) as well as homemade virgin coconut oil.

Separation by gas chromatography followed by mass spectrometry produced fragment ions that can be seen in Fig. 3, which were the fragment ions $(\mathrm{m} / \mathrm{z})$ of commercial fresh oil samples ( $\mathrm{Sc}$ and $\mathrm{Fc})$ and
Virgin coconut oil analyzed using FTIR showed that there were alkane and alkenes functional groups at wave numbers of around $3000 \mathrm{~cm}^{-1}$, carbony; (esters) at $1750 \mathrm{~cm}^{-1}$ and alkenes which strengthened in the region of $1680-1600 \mathrm{~cm}^{-1}$. Similar results were obtained for commercial essential products with stronger absorption as the marker of higher compound content.

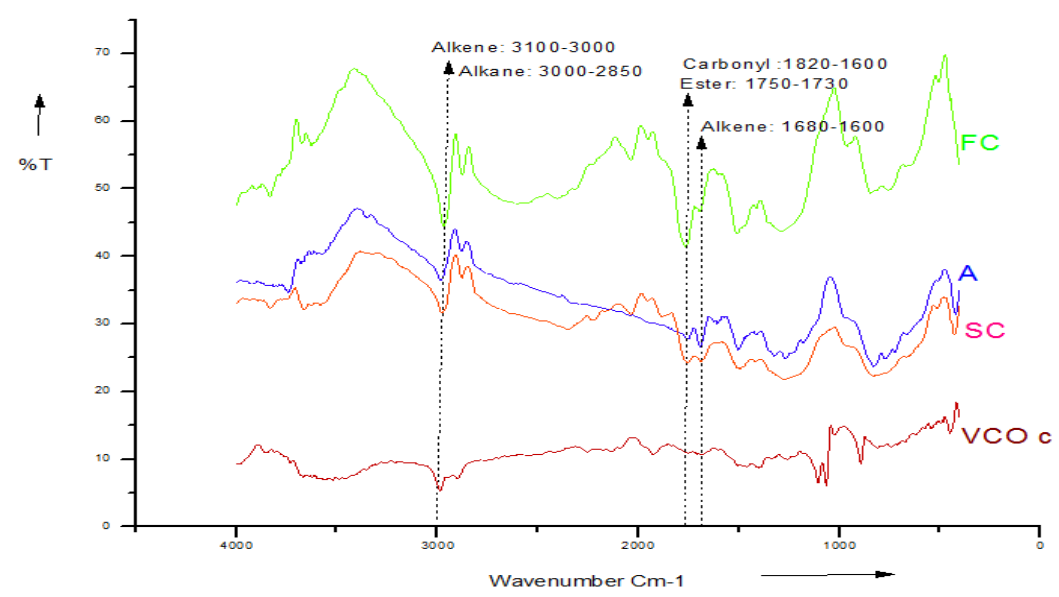

Fig. 2. Spectogram of FTIR some Fresh oil (Fc, A, Sc) and VCO control (VCOc)

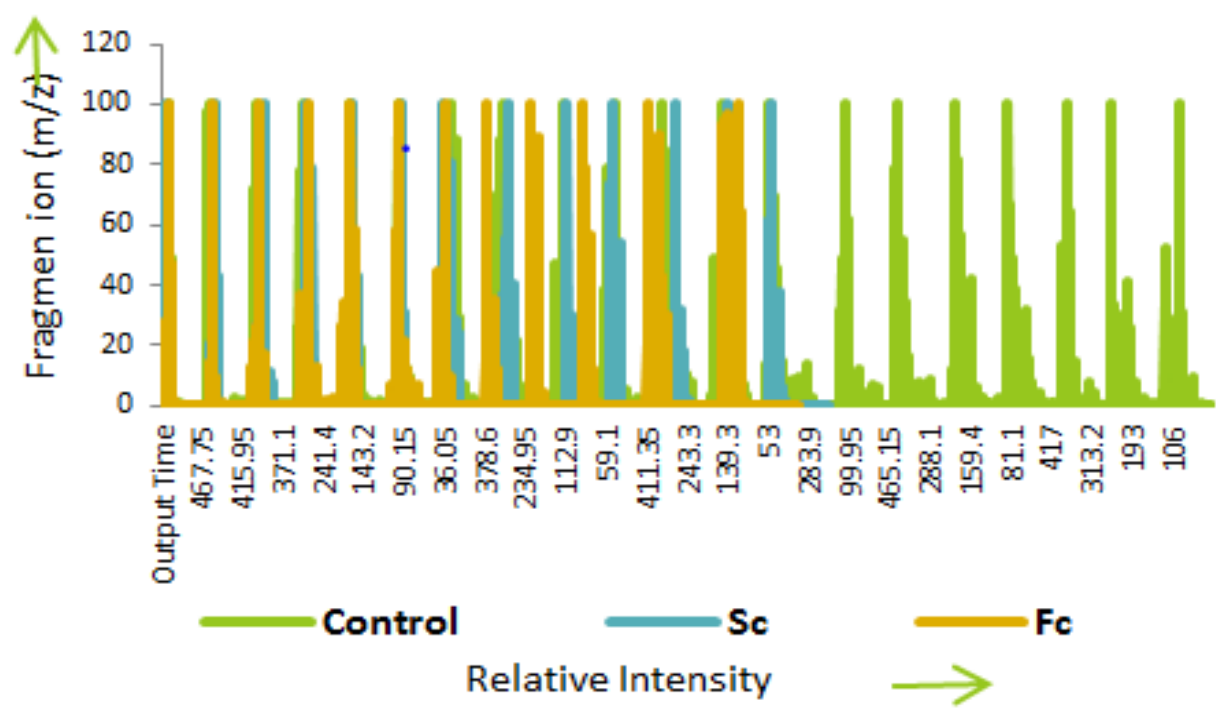

Fig. 3. Fragment ion of limonene and other antioxidant in commercial fresh oil ( $\mathrm{Sc}$ and $\mathrm{Fc}$ ) compared to homemade virgin coconut oil 
Analysis of commercial samples by GC-MS showed the presence of compounds of alpha pinene, delta-3-carene, beta pinene, alpha pheladrene, and dl limonene, but these results varied and were not the same in all samples and not detected in the sample of homemade virgin coconut oil. However, Erasto and Viljoen (2008) found that limonene was one of the monoterpene hydrocarbon compounds in the essential oil of aromatic plants. In addition to hydrocarbons both in the form of single and double bonds it was also found carbonyl functional groups in varying amounts, and the concentration was higher for commercial products compared to homemade VCO.

GC-MS as a modern analysis method has been developed for qualitative analysis with retention time markers adjusted to the NISH and Willey libraries, then the percentage results obtained were used for further analysis quantitatively. Fragments ions between homemade and commercial were also different which indicated that the preparation of homemade one was pure without the addition of compounds that have antioxidant potential. The quality of virgin coconut oil differed depending on the selected method of preparation where the highest oil content was obtained by inducement method followed by heating and fermentation (Pontoh et al., 2008).
This is supported by literature and published research by Harvey (2000); Silverstein et al., 1991; Kaluszna-Czaplinska (2007); Derwich et al. (2010), Ibrahimi et al. (2013) and Tomasz et al. (2013).

\section{CONCLUSIONS}

Limonene and other antioxidants such as pinene, careen, and phelandrene obtained quite good separation while was not detected in the homemade VCO characterized by GCMS. The analysis using FTIR of VCO and commercial essential oil products showed the presence of alkanes and esters functional groups at the wave numbers of $3000-2850$ and $1750-1730 \mathrm{~cm}^{-1}$ respectively.

\section{ACKNOWLEDGEMENT}

This study supported by National Grant from Research, Technology and Higher Education Ministry of Indonesia 2019 and LPPM Udayana University with the contract No. 492.22/UN 14.4.A/LT/2019.

\section{REFERENCES}

Kaluzna J.-Czaplinska. (2007). GC-MS Analysis of Biologically Active Compounds in Cosmopolitan Grasses. Acta Chromatographica 19, 279-282.

Pontoh J. Surbakti M. Br. Papilaya M. (2008). Kualitas Virgin Coconut Oil dari Beberapa Metode Pembuatan. Chemistry Progress. 1, (1), 60-65.

Derwich E. Benziane Z. Taouil R. (2010). GC/MS Analysis of Volatile 
Compounds of the Essential Oil of the Leaves of Mentha pulegium growing in Morocco. Chemical Bulletin of "Politehnica" University of Timisoara, Romania. 55,(69), 103106.

Ibrahimi M. H. Papajani V. Cavar S. Matevski V. (2013). GC/MS Analysis of the Essential Oil of Thymus Longicaulis Presl. From Kosovo. Bulletin of the Chemists and Technologists of Bosnia and Herzegovina 41, 6-10.

Tomasz BAJ. Ludwiczuk A. Seineawska E. Skalicka-Wozniak K. Widelski J. Sieba K. Gloniak K. 2013. GC-MS Analysis of Essential Oils from Salvia Officinalis L. Comparison of Extraction Methods of The Volatile components. Acta Poloniae Pharmaceutica-Drug Research. 70, (1), 35-40.

Harvey D. (2000). Modern Analytical Chemistry. $1^{\text {st }}$ ed. McGrawHillHigher Education. Singapore, Toronto. Ch. 10. pp. 446.

Silverstein RM, Bassler, G.C., and Morrill, T.C. (1991). Spectrometric Identification of Organic Compounds. $5^{\text {th }}$ Ed. Wiley. Ch. 2. pp. 3-16.

Erasto P. and Viljoen AM. (2008). Limonene- A Review: Biosynthetic, Ecological and Pharmacological Relevance. Natural Product Comunications. 3, (7), 1193-1202. 